\title{
Direct peroral cholangioscopic retrieval of an inward migrated plastic stent lodged in the cystic duct and liver hilum
}

Endoscopic sphincterotomy and stone extraction are widely performed as a primary intervention for patients with common bile duct (CBD) stones, with or without cholangiosepsis, with a high success rate and a relatively low complication rate [1]. When CBD stone removal is not successful, a plastic stent can be placed as a salvage therapy to achieve drainage, especially in the septic patient. It has also been shown that placement of biliary plastic stent prevents stone impaction and cholangitis [2]. The most common problem is stent migration occurring up to $5 \%$ proximal (into the duct) and $6 \%$ distal (out of the duct) [3]. Several techniques have been described to retrieve inward migrated stents with high success rates [4-5]. However, sometimes the endoprosthesis ends up in a very tricky position where your usual techniques might not be sufficient, as presented in the following case.

We present a case of a 90-year-old woman who presented to the emergency department with acute abdominal pain in the right upper quadrant, jaundice, fever, tachycardia, and hypotension. Computed tomography scan showed a large CBD stone with a dilated biliary tree ( $\vee$ Fig. $\mathbf{1}$ ). Under the working diagnosis of cholangiosepsis, intravenous fluids and antibiotics were initiated and a quick endoscopic retrograde cholangiopancreatography (ERCP) under conscious sedation (midazolam and fentanyl) was executed. After the endoscopic sphincterotomy was performed, a large 13-mm CBD stone was observed, which could not be retrieved with a basket/balloon. To ensure drainage, a 7-cm 10-Fr plastic endoprosthesis was placed in the common bile duct. The patient recovered well after this procedure and was discharged home after several days. An ERCP under deep sedation (propofol) was scheduled for the stone extraction 2 months later.

The previously placed endoprosthesis was not visible upon introduction. On

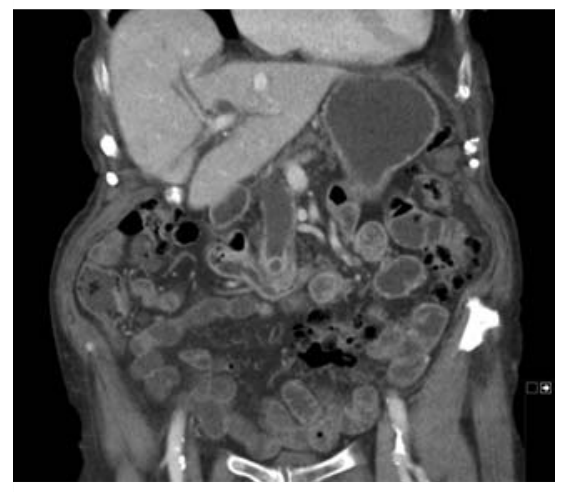

- Fig. 1 Coronal computer tomography showing a large common bile duct stone with dilated bile ducts.

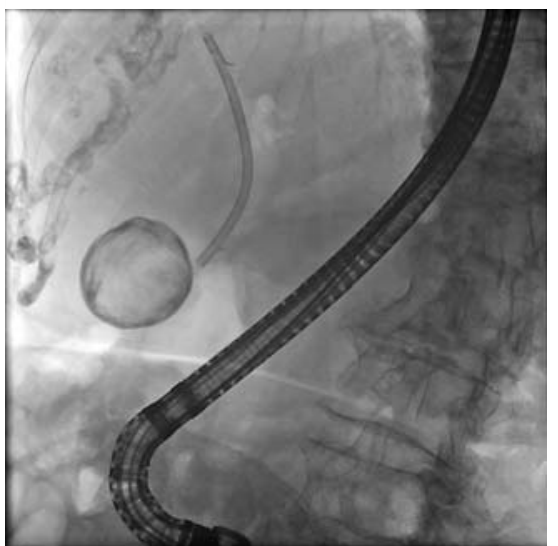

- Fig. 2 Fluoroscopic image showing large common bile duct stone with deeply inward migrated plastic endoprosthesis.

fluoroscopy, the 13-mm CBD stone was still in situ and the endoprosthesis appeared to be migrated deeply inwards into the liver ( $\triangleright$ Fig. 2). After dilatation of the ampulla, the CBD stone could be removed easily with an extraction balloon. Thereafter, multiple attempts to grasp the inward migrated stent were performed, however there was not enough grip to extract the stent ( $\mathbf{F i g . 3}$ ). Next, direct peroral cholangioscopy was used in an attempt to remove the stent under direct sight using an extraction balloon and grasping forceps ( $\triangleright$ Fig. 4). However,

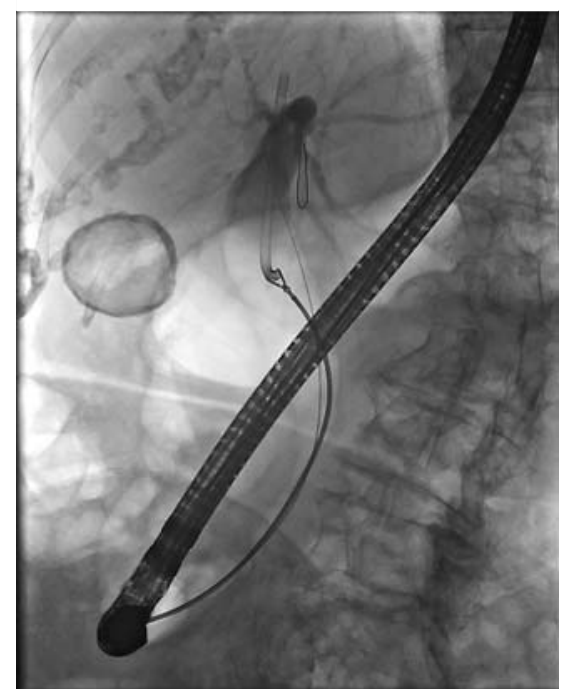

- Fig. 3 Fluoroscopic image showing an attempt to grab the plastic stent using a grasping forceps.

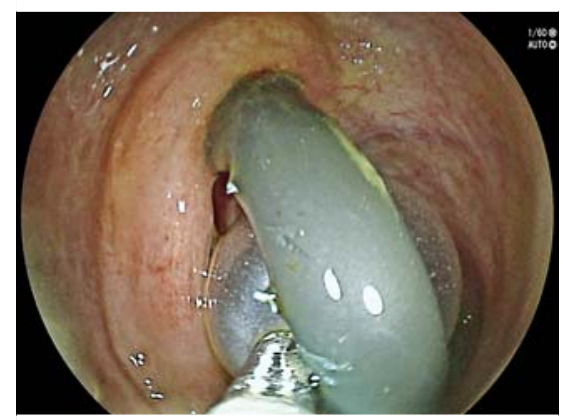

- Fig. 4 Direct peroral cholangioscopic image of attempt to remove the endoprosthesis with a balloon catheter.

we found that the distal end of the stent was stuck with the flank of the stent in the cystic duct.

So now what? Using a 1-mm snare and a 0.025 -inch guidewire (both through the same 2.4-mm working channel of the nasoendoscope), we finally succeeded in creating a grasping method to capture the stent ( $\triangleright$ Video $\mathbf{1}$ ). After tightening against the endoscope, the stent could be removed successfully ( $\triangleright$ Video 1 ). 


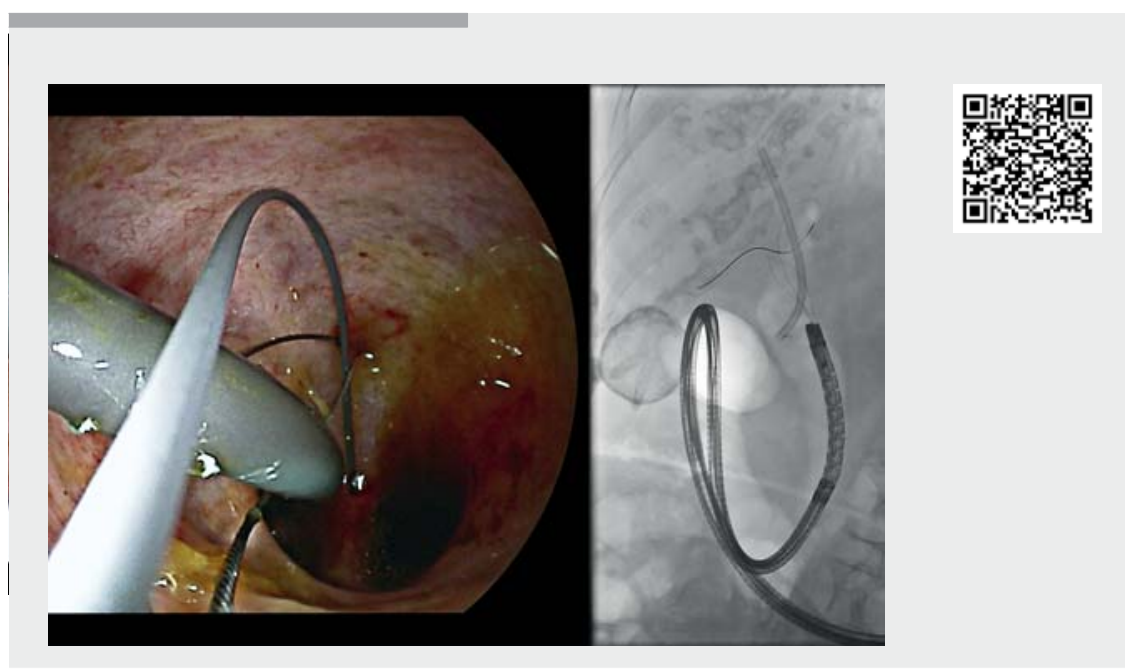

$\checkmark$ Video 1 Inward migrated plastic stent lodged in the cystic duct and liver hilum retrieved via direct peroral cholangioscopy.

This case shows an inventive method for a very uncommon problem. However, it highlights the endless possibilities that are available nowadays for endoscopic biliary interventions.

Endoscopy_UCTN_Code_CPL_1AK_2AD

Competing interests

The authors declare that they have no conflict of interest.

The authors

\section{Elmer Hoekstra, Roeland Veenendaal, Akin} Inderson

Department of Gastroenterology and Hepatology, Leiden Universitair Medisch Centrum (LUMC), Albinusdreef 2, Leiden, Netherlands
Corresponding author

\section{Elmer Hoekstra, MD}

Leiden Universitair Medisch Centrum (LUMC), Albinusdreef 2, 2333ZA, Leiden, Netherlands

Fax: +31-71-5248115

e.hoekstra@lumc.nl

\section{References}

[1] Vaira D, D’Anna L, Ainley C et al. Endoscopic sphincterotomy in 1000 consecutive patients. Lancet 1989; 2: 431-434

[2] Williams EJ, Green J, Beckingham I et al. Guidelines on the management of common bile duct stones (CBDS). Gut 2008; 57 : 1004-1021

[3] Johanson JF, Schmalz M], Geenen JE. Incidence and risk factors for biliary and pancreatic stent migration. Gastrointest Endosc 1992; 38: 341-346
[4] Chaurasia OP, Rauws EA, Fockens P et al. Endoscopic techniques for retrieval of proximally migrated biliary stents: the Amsterdam experience. Gastrointest Endosc 1999; 50: 780-785

[5] Tarnasky PR, Cotton PB, Baillie J et al. Proximal migration of biliary stents: attempted endoscopic retrieval in forty-one patients. Gastrointest Endosc 1995; 42: 513-520

\section{Bibliography}

Endoscopy 2021; 53: E330-E331

DOI 10.1055/a-1275-9571

ISSN 0013-726X

published online 23.10 .2020

(c) 2020. Thieme. All rights reserved.

Georg Thieme Verlag KG, Rüdigerstraße 14,

70469 Stuttgart, Germany

\section{ENDOSCOPY E-VIDEOS}

https:/|eref.thieme.de/e-videos

Endoscopy E-Videos is a free access online section, reporting 靣转: on interesting cases and new techniques in gastroenterological endoscopy. All papers include a high quality video and all contributions are freely accessible online.

This section has its own submission website at

https://mc.manuscriptcentral.com/e-videos 